\title{
Immigrant Generation and Diabetes Risk Among Mexican Americans: The Sacramento Area Latino Study on Aging
}

\author{
Aimee Afable-Munsuz, PhD, MPH [Research fellow], \\ Division of General Internal Medicine, Department of Medicine, University of California, San \\ Francisco \\ Elizabeth Rose Mayeda, MPH, \\ Department of Epidemiology and Biostatistics, University of California, San Francisco
}

Eliseo J. Pérez-Stable, MD, and Medical Effectiveness Research Center for Diverse Populations, Division of General Internal Medicine, Department of Medicine, University of California, San Francisco

Mary N. Haan, DrPH

Department of Epidemiology and Biostatistics, University of California, San Francisco

\begin{abstract}
Objectives-We examined whether acculturation and immigrant generation, a marker for assimilation, are associated with diabetes risk in an aging Mexican-origin population.

Methods-We analyzed data on 1789 adults aged 60 to 101 years from the Sacramento Area Latino Study on Aging. We ascertained type 2 diabetes on the basis of diabetic medication use, self-report of physician diagnosis, or a fasting glucose 126 milligrams/deciliter or greater. Logistic regression modeled prevalent diabetes.

Results-Adjusting for age and gender, we observed significant but divergent associations between immigrant generation, acculturation, and diabetes risk. Relative to first-generation adults, second-generation adults had an odds ratio OR) of $1.8(95 \%$ confidence interval $[\mathrm{CI}]=1.4,2.4)$ and third-generation adults had an OR of $2.1(95 \% \mathrm{CI}=1.4,3.1)$ of having diabetes. Greater US acculturation, however, was associated with a slightly decreased diabetes rate. In the full model adjusting for socioeconomic and lifestyle factors, the association between generation (but not acculturation) and diabetes remained significant.
\end{abstract}

Correspondence should be sent to Aimee Afable-Munsuz, MPH, PhD, Department of Community Health Sciences, SUNY Downstate School of Public Health, 450 Clarkson Avenue, Box 43, Brooklyn, New York 11203 (Aimee.afable-munsuz@downstate.edu).

Contributors

A. Afable-Munsuz originated the research study, wrote the first draft of the article, and supervised the analysis. E. R. Mayeda conducted all statistical analyses and reviewed drafts of the article. M. N. Haan was the principal investigator of the Sacramento Area Latino Study on Aging and assisted in the supervision of data analysis. M. N. Haan and E. J. Perez-Stable contributed to the conceptualization of the ideas and the interpretation of findings and reviewed drafts of the article.

Human Participant Protection

The institutional review boards of the University of Michigan, the University of California, Davis, and the University of California, San Francisco approved this study. 
Conclusions-Our study lends support to the previously contested notion that assimilation is associated with an increased diabetes risk in Mexican immigrants. Researchers should examine the presence of a causal link between assimilation and health more closely.

Diabetes is increasing in the United States ${ }^{1}$ and in countries that contribute the largest number of immigrants to the United States. ${ }^{2-4}$ These immigrant populations, who originate from countries where diabetes is prevalent, provide a unique opportunity to study the development of diabetes. They are a "high event" population because of possible genetic predisposition, ${ }^{5-8}$ and they experience rapid change in exposures; thus, they provide an efficient way to study the impact of environmental change on the progression of diabetes.

Immigrants are a large and dynamic segment of the US population. Between 1990 and 2000, the foreign-born population in the United States increased 57.0\%, from 19.8 million to 31.1 million, compared with an increase of $9.3 \%$ for the native population. ${ }^{9}$ It has been projected that $87.0 \%$ of the population growth between 2005 and 2050 will be driven by immigrants and their children. ${ }^{10}$ In California, for example, Latino children, many of whom are immigrants or children of immigrants, for the first time make up the majority of the population younger than 18 years. ${ }^{11}$

Mexico is the largest contributor of immigrants to the United States ${ }^{12}$ and has recently experienced rapid increases in both obesity and diabetes. ${ }^{13-15}$ From 1994 to 2006, the national prevalence of diabetes in Mexico more than doubled, going from $6.7 \%$ to $14.4 \% .^{13}$ This pattern is common in developing countries undergoing rapid urbanization. Social and economic change of rapid urbanization has led to more sedentary lifestyles and greater consumption of processed foods and calories, a process that has been labeled the "nutrition transition." 16,17

In the United States it is well known that relative to non-Latino Whites, Latinos-those of Mexican origin in particular-bear a much larger burden of diabetes. ${ }^{18-22}$ Because Latino immigrants constitute the largest proportion of immigrants to the United States by far, there has been interest in understanding whether acculturation to US lifestyles contributes to their heightened diabetes risk. The evidence on whether the risk of type 2 diabetes in Latino immigrant populations increases with greater time in the United States or acculturation, however, is mixed. ${ }^{23-27}$ It is well documented that immigrants arrive with a health advantage despite an adverse social and economic profile, possibly reflecting migration selectivity $28-33$ or the protective culture of immigrants, which encourages healthy behaviors and strong social support systems. ${ }^{34,35}$ Over time, however, immigrants and subsequent generations lose at least some of this initial health advantage. ${ }^{36,37}$ It is unknown whether diabetes contributes to the decline in the initial health advantage (sometimes called "unhealthy assimilation"). ${ }^{37}$ Furthermore, diabetes presents a unique case, as it is 1 of the few conditions for which evidence suggests that, relative to non-Latino Whites, Latinos carry a considerably higher risk and consequently are at a greater health disadvantage; it has been suggested that both genetics and environment contribute to this heightened risk. $6,32,38,39$

Although the Mexican national rate of diabetes is almost one and a half times higher than is the US rate, ${ }^{2,40}$ it is not clear whether the US setting slows or accelerates the development of 
diabetes. On the one hand, Mexican immigrants are moving from a country with high rates of diabetes to one with lower rates. But diabetes growth worldwide has also been attributed to global secular shifts in lifestyles and diet that result from upward social mobility and rapid urbanization. ${ }^{41-43}$ Because Mexican immigrants to the United States are moving to a more affluent society, it would also be reasonable to postulate that their diabetes risk will be heightened with longer time or after several generations of living in the United States. ${ }^{44}$

Some studies have examined whether diabetes increases with longer US residence in middle-aged populations ${ }^{24,26}$; however, we are the first, to our knowledge, to focus on an aging Mexican-origin population, aged 60 years and older. We also examined whether there is significant heterogeneity in diabetes risk across different generations. Consistent with the unhealthy assimilation perspective, ${ }^{37}$ we examined whether diabetes risk increases from the immigrant generation to US-born second and third generations, using data from the Sacramento Area Latino Study on Aging (SALSA).

\section{METHODS}

Participants in this study were members of the SALSA cohort. SALSA is a longitudinal cohort study (1997-2008) of 1789 community-dwelling Mexican Americans residing in California's Sacramento Valley, aged 60 to 101 years at baseline in 1998-1999. The study population and the participant recruitment procedure have been described elsewhere. ${ }^{45}$ Briefly, to be eligible for the study, participants had to be residents of the Sacramento metropolitan statistical area and surrounding suburban and rural counties. An eligible person was aged 60 years or older in 1998 and self-designated as Latino. The sample was highly representative of older Latinos residing in the Sacramento area. In a 2-hour interview, each participant answered survey questions about lifestyle factors, acculturation, and medical diagnoses. ${ }^{45}$ Trained interviewers also collected anthropometric measurements and drew fasting blood for measurement of lipids, antioxidants, glucose, and insulin. In-home visits were conducted every 12 to 15 months for a total of 7 follow-up visits. Interviews were conducted in Spanish or English, according to the respondent's choice. We used only data collected during the baseline interview for our analysis.

\section{Diabetes Ascertainment}

All SALSA respondents were screened for type 2 diabetes mellitus. We ascertained diabetes by determining use of a diabetic medication, self-report of a physician's diagnosis, or fasting glucose of 126 milligrams/deciliter or greater.

Trained research staff obtained blood during the in-home interview and measured fasting glucose by standard venipuncture. Staff obtained information on medication by medicine chest inventory during the in-home interview.

\section{Immigrant Generation and Acculturation}

Sociologists who study the assimilation process among US immigrants view immigrant generation as a central variable conceptualized broadly as a time dimension reflecting increasing exposure to US social and cultural norms. ${ }^{46}$ We assessed immigrant generation on the basis of nativity of the respondent and the respondent's parents, as reported by the 
respondent. We classified a foreign-born respondent as a first-generation immigrant and a US-born respondent with at least 1 foreign-born parent as second generation; if the respondent and both parents were born in the United States, we classified him or her as third generation. ${ }^{47,48}$

From a sociological perspective, assimilation entails both social mobility and the extent to which the immigrant population achieves social and economic parity with the native population (i.e., whether the number of those with a college education increases across generations of Mexicans and reaches the number of native Whites) as well as acculturation or the gradual adoption of the traits of the host culture with a loss of those from their home country. ${ }^{49}$ To measure the concept of acculturation, we used 10 items from the Acculturation Rating Scale for Mexican-Americans II scale, which assessed English and Spanish language and media use (6 items) and affinity toward Latino friendships (4 items). The scoring procedures were similar to those Cuellar et al.$^{50}$ recommended, resulting in a variable with a range of 0 to 6 , with higher scores representing greater US acculturation. We also assessed language of interview in the descriptive analysis.

\section{Covariates}

Demographic factors included age (continuous) and gender. We selected additional covariates according to their potential association with immigrant generation, because they were thought to be potential mediators on the causal pathway between assimilation, acculturation, and diabetes risk. ${ }^{23-27,51}$ Socioeconomic status (SES) factors included education (number of years), income sources, lifetime occupation, and health insurance status (whether they had insurance coverage). We derived income source from questions that assessed whether the respondent received any earned income (salary, pension, social security, or veterans benefits) or entitled income (disability, supplemental social security, housing subsidy, or food stamps). We grouped lifetime occupation into non-manual (e.g., managerial, professional, and administrative support), manual (e.g., farming, machine operation, and transportation), and no occupation or homemaker. Lifestyle factors included smoking (current, past, or never smoker), alcohol use, and physical activity, which are all known to vary by acculturation and to be associated with diabetes risk. ${ }^{48,52,53}$

We determined physical activity on the basis of a question that asked the respondent to classify usual outdoor walking pace (easy or casual; normal or average; brisk pace; very brisk or striding; and never walk outdoors). We measured waist circumference (in inches) at the level of maximum indentation over the abdomen when the participant bent to the side. We calculated body mass index (BMI) using the formula weight in kilograms divided by the square of height in meters.

\section{Analytic Procedures}

We compared differences in sociodemographic characteristics, health behaviors, and study outcomes by immigrant generation with the $\chi^{2}$ test for categorical variables and analysis of variance for continuous variables. In the modeling stage, we examined 4 different logistic regression models predicting prevalent diabetes. First, we examined the effect of generation and acculturation on diabetes risk, adjusting for age and gender. Second, we added all SES 
measures and lifestyle factors separately to examine whether their addition attenuated the relationship between generation and diabetes risk. Finally, in the full model we adjusted for all covariates at once. We performed all analyses in SAS version 9.2 (SAS Institute, Cary, $\mathrm{NC}) .{ }^{54}$

Because $17 \%$ of the participants had missing data on waist circumference, a key variable of the analysis, we performed a multiple imputation approach for the entire SALSA data set to accommodate incomplete data points. This was a sequential regression multivariate imputation approach that conditions on all observed variables as predictors. ${ }^{55,56}$ The multiple imputation approach for SALSA has been described in detail elsewhere. ${ }^{57} \mathrm{We}$ performed sensitivity analyses using the nonimputed SALSA data set. We reached similar conclusions, with unchanged statistical significance compared with the analysis using multiple imputations. We used data from baseline in this analysis.

\section{RESULTS}

Overall, 58\% of the SALSA participants were women. A majority (58\%) had a Spanishlanguage interview. The mean number of years of education was $7.2,43 \%$ reported 2 or more earned income sources (with no entitled income sources), and 59\% had a manual lifetime occupation (Table 1). A large majority (81\%) reported infrequent alcohol use, currently not smoking (89\%), and a casual or average walking pace (74\%). The mean BMI of SALSA participants at baseline was 30. Mean waist circumference was 38 inches. Overall, we classified $21 \%$ as having a diabetes diagnosis on the basis of medication alone and another $12 \%$ as having diabetes who were not taking medication; this resulted in our classifying $33 \%$ of all SALSA baseline respondents as having diabetes.

More than half of the SALSA participants were first-generation, about $40 \%$ were secondgeneration (respondent born in the United States but at least 1 foreign-born parent), and 9\% were third-generation (respondent and both parents born in the United States) immigrants. Every indicator in Table 1 varied by immigrant generation with the exceptions of gender and smoking status. The proportion of respondents who completed the interview in English ranged from $14 \%$ in the first generation to about $88 \%$ in the third generation. Similarly, the mean acculturation score ranged from 1.3 among the first generation to 3.5 among the third generation (score range $=0-6$ ). SES indicators also varied by immigrant generation. For example, the proportion reporting 2 or more earned income sources (with no entitled income source) ranged from $34 \%$ among first generation to about $56 \%$ among the third generation. Reports of brisk walking pace ranged from $14 \%$ in the first generation to $21 \%$ in the third generation. Finally, the proportion with a diabetes diagnosis ranged from $29 \%$ in the first generation to $39 \%$ in the third generation.

In the unadjusted analysis (Table 2), the generation and acculturation scores were both significantly associated with diabetes risk but had inverse relationships; for example, the odds of diabetes risk were significantly higher for third generation (vs first generation; odds ratio $[\mathrm{OR}]=2.09 ; 95 \%$ confidence interval $[\mathrm{CI}]=1.42,3.11$, but the odds decreased with increasing acculturation ( $\mathrm{OR}=0.88 ; 95 \% \mathrm{CI}=0.80,0.95)$. We also assessed other logistic regression models. For example, in separate models, we assessed whether generation, 
acculturation, and language of interview independently predicted diabetes risk, and only generation had a significant association with diabetes risk (acculturation OR $=1.01 ; 95 \% \mathrm{CI}$ $=0.95,1.08$; language of interview $\mathrm{OR}=1.07 ; 95 \% \mathrm{CI}=0.88,1.31)$.

We tested whether there was a significant difference in diabetes risk between second and third generations; however, the difference was not statistically significant when comparing third to second generation $(\mathrm{OR}=1.09 ; 95 \% \mathrm{CI}=0.77,1.55)$. Finally, we examined whether there was an association between number of years in the United States and diabetes risk among the immigrant sample. However, the association was not statistically significant (OR $=1.00 ; 95 \% \mathrm{CI}=0.99,1.00)$.

After adjusting for SES variables and lifestyle factors separately (Table 2), the significant association between generation and diabetes risk remained (e.g., after adjusting for lifestyle factors, comparing third to first generation, $\mathrm{OR}=2.02 ; 95 \% \mathrm{CI}=1.31,3.11$ ), but the association between acculturation and diabetes risk was no longer significant. It is notable that in the full model, which adjusts for lifestyle and SES factors, the positive association between increasing generation and diabetes risk remained; compared with first generation, the odds for second $(\mathrm{OR}=1.75 ; 95 \% \mathrm{CI}=1.30,2.33)$ and third $(\mathrm{OR}=2.00 ; 95 \% \mathrm{CI}=1.29$, 3.10) generations were significantly higher. Waist circumference was also a strong predictor of diabetes risk in the full model $(\mathrm{OR}=1.08 ; 95 \% \mathrm{CI}=1.05,1.10)$. We also assessed BMI, in place of waist circumference, in the full model, and it was also significant $(\mathrm{OR}=1.04$; $95 \% \mathrm{CI}=1.02,1.05)$. In light of evidence that waist circumference is a more sensitive predictor of diabetes risk in the elderly and in ethnic minority groups including individuals of Mexican origin, ${ }^{58,59}$ we have presented findings for waist circumference. It is also notable that in the full model frequent or moderate versus occasional or never alcohol use was strongly associated with a decreased risk of diabetes in the full model $(\mathrm{OR}=0.39 ; 95 \% \mathrm{CI}=$ $0.28,0.54)$, and brisk walking pace versus casual, infrequent, or never walking was moderately associated with a decreased risk of diabetes $(\mathrm{OR}=0.75 ; 95 \% \mathrm{CI}=0.55,1.03)$.

\section{DISCUSSION}

Our study suggests that immigrant generation is significantly associated with diabetes risk among our population-based sample of aging adults of Mexican origin. Diabetes risk is higher in US-born second- and third-generation individuals compared with immigrants. These associations are not influenced by acculturation, SES, or the lifestyle factors we measured. Of the SES and lifestyle factors we examined, only alcohol consumption was significantly associated with diabetes in multivariate models at the $P<.01$ level.

Our study also suggests that immigrant generation and acculturation, although strongly associated with each other (Table 1), capture different dimensions of immigrants' adaptation process to the United States. First, unlike immigrant generation, which was positively associated with diabetes risk, acculturation had an inverse association with diabetes risk in the unadjusted model. Second, the association between immigrant generation and diabetes risk persisted even after accounting for all study covariates; this was not the case for acculturation. This latter relationship was somewhat attenuated after adjusting for SES factors. These findings are consistent with results of past studies. ${ }^{23-25,41}$ Although longer 
US residence (derived from generation and time measures) has been associated with increased risk of diabetes, ${ }^{23,24}$ acculturation (derived from language preference and ethnic identification) has been associated with a decreased risk of diabetes in diverse immigrant populations. ${ }^{25,60,61}$ These empirical findings have been replicated in previous studies that used multiple measures of acculturation in relation to diabetes and other health indicators. 61,62

Although these findings can be interpreted as inconsistent, they may also suggest that different measures of acculturation are proxies for different mechanisms and point to the complexity of the adaptation process of immigrants to the United States. In addition to changes in language preferences or ethnic identities-common constructs captured in acculturation measures used in existing health studies - there are many other dimensions to immigrants' transition and adaptation to the United States. ${ }^{63-65}$ With regard to existing measures of acculturation, particularly those that rely on language use or preference, socioeconomic factors are likely to confound the relationship between acculturation level and health. ${ }^{64}$ The addition of SES factors to our model slightly $(6 \%)$ attenuated the association between the acculturation measure used and diabetes risk, and so our study provides evidence to support this contention.

From a broader perspective, increasing generations can be viewed as a marker of cumulative exposure to a new social, cultural, and physical environment. It is notable that the vast majority (more than 65\%) of the first-generation SALSA participants migrated to the United States as adults. In this regard, our study provides evidence of an immigrant health advantage whereby being raised as a child in their home country of Mexico affords some protective effect on health, which then diminishes in subsequent generations. This interpretation leaves open the question of whether culture, environment, selection, or some combination of these factors explains our findings. Relating our findings to global changes in lifestyles and patterns in obesity and diabetes, however, may help elucidate some of the causal pathways implicated in this process of unhealthy assimilation. ${ }^{43,66,67}$ Intra-country migrants who move from rural to urban areas or who transition from poverty to affluence, for example, can take on more sedentary jobs, which are markedly different from their former labor-intensive work, and adopt less healthy diets. ${ }^{68,69}$ Migrants whomove from their home country to the United States seeking better economic opportunities undergo similar, perhaps more dramatic changes.

The implications of chronic stress associated with immigrants' new lifestyles in the United States, which are increasingly constrained by time and more demanding occupations, are largely unexplored. It is unknown, for example, whether the cumulative impact of exposure to repeated stressors or how the life course timing of exposure to stressors contributes to this heightened diabetes risk. Using National Health and Nutrition Examination Survey data, for example, Kaestner et al. ${ }^{70}$ found that the impact of chronic stress, as measured by allostatic load, among older Mexican immigrants is lower on arrival in the United States, compared with US-born Mexican Americans or non-Latino Whites or Blacks; this health advantage decreased with greater time in the United States. ${ }^{70}$ 
Furthermore, health behaviors of immigrants are transformed by prevailing US ideologies concerning diet and nutrition, ${ }^{71-73}$ and how the food culture of immigrant populations evolves from the immigrant generation to the US-born generations is central to understanding diabetes development. Chronic exposure to the US built environment (e.g., walkability, proximity to grocery stores, public transit), which is increasingly characterized as obesogenic,${ }^{74,75}$ may also play an important role in accelerating the development of diabetes in US immigrants. ${ }^{76}$ Future studies should examine more closely and in greater detail transformations in immigrants' dietary and physical activity patterns, relationships to food and food preparation, the physical environment, and stress biomarkers as potential mediators or moderators of the relationship between assimilation and diabetes risk.

Finally, there is evidence that points to an increased susceptibility to diabetes among Mexican-origin populations in the United States because of genetic predisposition., 577 Given this background, studies that try to better understand mechanisms of determining onset of diabetes in Mexican-origin populations are even more relevant. The Mexican-origin population and higher event rate populations present unique opportunities to disentangle and study the role of genetics and how it may interact with chronic stressors and change in environments and behaviors. ${ }^{78}$

\section{Limitations and Considerations for Future Research}

Because we relied on cross-sectional data used from the SALSA baseline wave, it was beyond our scope to estimate temporal effects, which would help to establish causality. It is possible, for example, that the observed inverse association between alcohol use and diabetes risk has a reverse causal relationship such that diabetes diagnosis would cause respondents who report alcohol use to drink less whereas the undiagnosed respondents continued to drink as usual. The overall prevalence, however, of alcohol use in our sample was low, so this pattern may apply to only a small proportion of the respondents. We assessed only outdoor walking pace, which possibly underestimates physical activity levels; SALSA participants may also engage in other forms of leisure and nonleisure (e.g., job-, housework-, or transportation-related) activity. SALSA did not collect any dietary measures, and thus we were unable to examine the potential role that dietary change played in the relationship between assimilation and diabetes risk.

Cross-sectional studies of immigrants do not allow us to study key dynamic aspects of immigration at the individual level. ${ }^{79}$ We had a cross-section of different generations in our study. Therefore, each generation may have come from a different migration cohort and thus have had a different migration experience. ${ }^{37}$ Immigrant (first-generation) versus native-born (second- and third-generation) participants in our study may have come from different ancestral and regional groups in Mexico, who are diverse in genetic admixture ${ }^{80,81}$ and social characteristics. This diversity may result in variations in diabetes risk. ${ }^{82}$ Family intergenerational studies (parents and their offspring), prospective cohort studies of new immigrants followed at regular intervals, ${ }^{79}$ and binational studies of migrants and their nonmigrant counterparts ${ }^{4,83}$ would allow us to control for heterogeneity by place of origin, to study adaptation over time, and to assess immigrant selection. Finally, our measure of acculturation was a short adaptation of a previously validated scale. ${ }^{50}$ Acculturation is 
complex and requires extensive measurement, but such scales are time consuming and impractical and it is still unclear whether these more extensive scales have explanatory power over the shorter or 1-item language proxies in health studies. ${ }^{84}$

\section{Conclusions}

Relationships between migration, acculturation, and health are complex,${ }^{85}$ and both negative and positive associations between assimilation, acculturation, and diabetes and its risk factors have been observed. ${ }^{23-27,37,48,86,87}$ This evidence from the health literature is not surprising given the heterogeneity of acculturation and assimilation processes in US immigrants, which scholars of migration have described. ${ }^{88}$ Our study adds to the evidence on the adverse associations between accumulating exposure to US environment and diabetes risk and other health indicators in immigrants to the United States. It also highlights the need to employ more novel designs to evaluate whether there is a causal link between assimilation and poor health and, if so, to more closely examine potential mechanisms. We also suggest that such examinations would be of benefit when placed in the context of the global epidemic of diabetes.

\section{Acknowledgments}

This research project was supported by the University of California, San Francisco Clinical and Translational Science Institute and the National Center for Research Resources (grant UL 1 RR024131 to A. A.), the Resource Centers for Minority Aging Research (grant P30-AG15272 to E. J. P.), and the National Institutes of Health ([NIH] grants AG12975 and DK60753 to M. N. H.).

The authors wish to thank Steven Gregorich and John M. Neuhaus for their statistical guidance on earlier stages of this project.

Note. The contents of this article are solely the responsibility of the authors and do not necessarily represent the official views of the NIH.

\section{References}

1. Centers for Disease Control and Prevention. Diabetes Data and Trends. Department of Health and Human Services; 2010. Available at: http://www.cdc.gov/diabetes/statistics/prev/national/ figage.htm. [Accessed November 5, 2010]

2. Villalpando S, Rojas R, Shamah-Levy T, et al. Prevalence and distribution of type 2 diabetes mellitus in Mexican adult population. A probabilistic survey. Salud Publica Mex. 2010; 52(suppl 1):S19-S26. [PubMed: 20585724]

3. Yang SH, Dou KF, Song WJ. Prevalence of diabetes among men and women in China. N Engl J Med. 2010; 362(25):2425-2426.

4. Soria ML, Sy RG, Vega BS, et al. The incidence of type 2 diabetes mellitus in the Philippines: a 9year cohort study. Diabetes Res Clin Pract. 2009; 86(2):130-133. [PubMed: 19766344]

5. Gardner LI Jr, Stern MP, Haffner SM, et al. Prevalence of diabetes in Mexican Americans. Relationship to percent of gene pool derived from native American sources. Diabetes. 1984; 33(1): 86-92. [PubMed: 6690348]

6. Stern MP, Knapp JA, Hazuda HP, Haffner SM, Patterson JK, Mitchell BD. Genetic and environmental determinants of type II diabetes in Mexican Americans. Is there a "descending limb" to the modernization/diabetes relationship? Diabetes Care. 1991; 14(7):649-654. [PubMed: 1914814]

7. Elbein SC. Genetics factors contributing to type 2 diabetes across ethnicities. J Diabetes Sci Technol. 2009; 3(4):685-689. [PubMed: 20144314] 
8. Haffner SM. Epidemiology of type 2 diabetes: risk factors. Diabetes Care. 1998; 21(suppl 3):C3C6. [PubMed: 9850478]

9. Malone, N, Baluja, K, Costanzo, J, Davis, C. Census 2000 brief. Washington, DC: US Bureau of the Census; 2003. The Foreign-Born Population: 2000.

10. Passel, JS, Cohn, DU. U.S. Population Projections: 2005-2050. Washington, DC: Pew Research Center; 2008.

11. Carlton J. Hispanics surge in California. Wall Street Journal. 2011 Mar 9.Accessed March 11, 2011

12. Grieco, P. Race and Hispanic Origin of the Foreign-Born Population in the United States: 2007. Washington, DC: US Census Bureau; 2009. American Community Survey report no. ACS-11.

13. Aguilar-Salinas CA, Velazquez Monroy O, Gomez-Perez FJ, et al. Characteristics of patients with type 2 diabetes in Mexico: results from a large population-based nationwide survey. Diabetes Care. 2003; 26(7):2021-2026. [PubMed: 12832306]

14. Jiménez-Cruz A, Bacardi-Gascon M. The fattening burden of type 2 diabetes on Mexicans: projections from early growth to adulthood. Diabetes Care. 2004; 27(5):1213-1215. [PubMed: 15111551]

15. Rivera JA, Barquera S, Campirano F, Campos I, Safdie M, Tovar V. Epidemiological and nutritional transition in Mexico: rapid increase of non-communicable chronic diseases and obesity. Public Health Nutr. 2002; 5(1A):113-122. [PubMed: 12027273]

16. Popkin BM. The nutrition transition: an overview of world patterns of change. Nutr Rev. 2004; 62(7 pt 2):S140-S143. [PubMed: 15387480]

17. Rivera JA, Barquera S, Gonzalez-Cossio T, Olaiz G, Sepulveda J. Nutrition transition in Mexico and in other Latin American countries. Nutr Rev. 2004; 62(7 pt 2):S149-S157. [PubMed: 15387482]

18. Hamman RF, Marshall JA, Baxter J, et al. Methods and prevalence of non-insulin-dependent diabetes mellitus in a biethnic Colorado population. The San Luis Valley Diabetes Study. Am J Epidemiol. 1989; 129(2):295-311. [PubMed: 2912042]

19. Flegal KM, Ezzati TM, Harris MI, et al. Prevalence of diabetes in Mexican Americans, Cubans, and Puerto Ricans from the Hispanic Health and Nutrition Examination Survey, 1982-1984. Diabetes Care. 1991; 14(7):628-638. [PubMed: 1914812]

20. Harris MI, Flegal KM, Cowie CC, et al. Prevalence of diabetes, impaired fasting glucose, and impaired glucose tolerance in U.S. adults. The Third National Health and Nutrition Examination Survey, 1988-1994. Diabetes Care. 1998; 21(4):518-524. [PubMed: 9571335]

21. Cowie CC, Rust KF, Byrd-Holt DD, et al. Prevalence of diabetes and high risk for diabetes using A1C criteria in the U.S. population in 1988-2006. Diabetes Care. 2010; 33(3):562-568. [PubMed: 20067953]

22. Stern MP, Gaskill SP, Hazuda HP, Gardner LI, Haffner SM. Does obesity explain excess prevalence of diabetes among Mexican Americans? Results of the San Antonio Heart Study. Diabetologia. 1983; 24(4):272-277. [PubMed: 6862133]

23. Oza-Frank R, Stephenson R, Venkat Narayan KM. Diabetes prevalence by length of residence among US immigrants. J Immigr Minor Health. 2011; 13(1):1-8. [PubMed: 19688263]

24. Ahmed AT, Quinn VP, Caan B, Sternfeld B, Haque R, Van Den Eeden SK. Generational status and duration of residence predict diabetes prevalence among Latinos: the California Men's Health Study. BMC Public Health. 2009; 9:392. [PubMed: 19840393]

25. Hazuda HP, Haffner SM, Stern MP, Eifler CW. Effects of acculturation and socioeconomic status on obesity and diabetes in Mexican Americans. The San Antonio Heart Study. Am J Epidemiol. 1988; 128(6):1289-1301. [PubMed: 3195568]

26. Kandula NR, Diez-Roux AV, Chan C, et al. Association of acculturation levels and prevalence of diabetes in the Multi-Ethnic Study of Atherosclerosis (MESA). Diabetes Care. 2008; 31(8):16211628. [PubMed: 18458142]

27. Mainous AG 3rd, Majeed A, Koopman RJ, et al. Acculturation and diabetes among Hispanics: evidence from the 1999-2002 National Health and Nutrition Examination Survey. Public Health Rep. 2006; 121(1):60-66. [PubMed: 16416699]

28. Palloni A, Arias E. Paradox lost: explaining the Hispanic adult mortality advantage. Demography. 2004; 41(3):385-415. [PubMed: 15461007] 
29. Rubalcava LN, Teruel GM, Thomas D, Goldman N. The healthy migrant effect: new findings from the Mexican Family Life Survey. Am J Public Health. 2008; 98(1):78-84. [PubMed: 18048791]

30. Marmot MG, Adelstein AM, Bulusu L. Lessons from the study of immigrant mortality. Lancet. 1984; 1(8392):1455-1457. [PubMed: 6145889]

31. Goel MS, McCarthy EP, Phillips RS, Wee CC. Obesity among US immigrant subgroups by duration of residence. JAMA. 2004; 292(23):2860-2867. [PubMed: 15598917]

32. Markides KS, Coreil J. The health of Hispanics in the southwestern United States: an epidemiologic paradox. Public Health Rep. 1986; 101(3):253-265. [PubMed: 3086917]

33. Hummer RA, Rogers RG, Nam CB, LeClere FB. Race/ethnicity, nativity, and U.S. adult mortality. Soc Sci Q. 1999; 80(1):136-153.

34. Cattell V. Poor people, poor places, and poor health: the mediating role of social networks and social capital. Soc Sci Med. 2001; 52(10):1501-1516. [PubMed: 11314847]

35. Kawachi, I, Berkman, L. Social cohesion, social capital, and health. In: Berkman, L, Kawachi, I, editorsSocial Epidemiology. Oxford: Oxford University Press; 2000. 174-190.

36. Angel RJ, Angel JL, Diaz Venegas CD, Bonazzo C. Shorter stay, longer life: age at migration and mortality among the older Mexican-origin population. J Aging Health. 2010; 22(7):914-931. [PubMed: 20682948]

37. Antecol H, Bedard K. Unhealthy assimilation: do immigrants converge to American health status levels? Demography. 2006; 43(2):337-360. [PubMed: 16889132]

38. Vega WA, Amaro H. Latino outlook: good health, uncertain prognosis. Annu Rev Public Health. 1994; 15:39-67. [PubMed: 8054092]

39. Stern MP, Gonzalez C, Mitchell BD, Villalpando E, Haffner SM, Hazuda HP. Genetic and environmental determinants of type II diabetes in Mexico City and San Antonio. Diabetes. 1992; 41(4):484-492. [PubMed: 1607073]

40. Centers for Disease Control and Prevention. National Diabetes Fact Sheet: General Information and National Estimates on Diabetes in the United States, 2007. Atlanta: US Department of Health and Human Services; 2008.

41. Fujimoto WY, Bergstrom RW, Boyko EJ, et al. Diabetes and diabetes risk factors in second- and third-generation Japanese Americans in Seattle, Washington. Diabetes Res Clin Pract. 1994; 24(suppl):S43-S52. [PubMed: 7859632]

42. Kawate R, Yamakido M, Nishimoto Y, Bennett PH, Hamman RF, Knowler WC. Diabetes mellitus and its vascular complications in Japanese migrants on the Island of Hawaii. Diabetes Care. 1979; 2(2):161-170. [PubMed: 520120]

43. Popkin BM, Gordon-Larsen P. The nutrition transition: worldwide obesity dynamics and their determinants. Int J Obes Relat Metab Disord. 2004; 28(suppl 3):S2-S9. [PubMed: 15543214]

44. Ullmann SH, Goldman N, Massey DS. Healthier before they migrate, less healthy when they return? The health of returned migrants in Mexico. Soc Sci Med. 2011; 73(3):421-428. [PubMed: 21729820]

45. Haan MN, Mungas DM, Gonzalez HM, Ortiz TA, Acharya A, Jagust WJ. Prevalence of dementia in older Latinos: the influence of type 2 diabetes mellitus, stroke and genetic factors. J Am Geriatr Soc. 2003; 51(2):169-177. [PubMed: 12558712]

46. Portes, A. The New Second Generation. New York: Russell Sage Foundation; 1996.

47. Bates LM, Acevedo-Garcia D, Alegria M, Krieger N. Immigration and generational trends in body mass index and obesity in the United States: results of the National Latino and Asian American Survey, 2002-2003. Am J Public Health. 2008; 98(1):70-77. [PubMed: 18048787]

48. Afable-Munsuz A, Ponce N, Perez-Stable E, Rodriguez M. Immigrant generation and physical activity among Mexican, Chinese and Filipino adults in the U.S. Soc Sci Med. 2010; 70(12):19972005. [PubMed: 20378226]

49. Portes A, Rivas A. The adaptation of migrant children. Future Child. 2011; 21(1):219-246. [PubMed: 21465862]

50. Cuellar I, Arnold B, Maldonado R. Acculturation Rating Scale for Mexican Americans-II: a revision of the original ARSMA scale. Hisp J Behav Sci. 1995; 17:275-304. 
51. Baron RM, Kenny DA. The moderator-mediator variable distinction in social psychological research: conceptual, strategic, and statistical considerations. J Pers Soc Psychol. 1986; 51(6): 1173-1182. [PubMed: 3806354]

52. Baliunas DO, Taylor BJ, Irving H, et al. Alcohol as a risk factor for type 2 diabetes: a systematic review and meta-analysis. Diabetes Care. 2009; 32(11):2123-2132. [PubMed: 19875607]

53. Willi C, Bodenmann P, Ghali WA, Faris PD, Cornuz J. Active smoking and the risk of type 2 diabetes: a systematic review and meta-analysis. JAMA. 2007; 298(22):2654-2664. [PubMed: 18073361]

54. SAS/STAT, Version 9.1.3. Cary, NC: SAS Institute; 2008. [computer program].

55. Rubin, DB. Multiple Imputation for Nonresponse in Surveys. New York: John Wiley \& Sons; 1987.

56. Raghunathan TE, Lepkowski JM, Van Hoewyk J. A multivariate technique for multiply imputing missing values using a sequence of regression models. Surv Methodol. 2001; 27(1):83-95.

57. Zeki Al Hazzouri A, Haan MN, Kalbfleisch JD, Galea S, Lisabeth LD, Aiello AE. Life-course socioeconomic position and incidence of dementia and cognitive impairment without dementia in older Mexican Americans: results from the Sacramento Area Latino Study on Aging. Am J Epidemiol. 2011; 173(10):1148-1158. [PubMed: 21430188]

58. Wannamethee SG, Papacosta O, Whincup PH, et al. Assessing prediction of diabetes in older adults using different adiposity measures: a 7 year prospective study in 6,923 older men and women. Diabetologia. 2010; 53(5):890-898. [PubMed: 20146052]

59. Diaz VA, Mainous AG 3rd, Baker R, Carnemolla M, Majeed A. How does ethnicity affect the association between obesity and diabetes? Diabet Med. 2007; 24(11):1199-1204. [PubMed: 17725630]

60. Kaholokula JK, Nacapoy AH, Grandinetti A, Chang HK. Association between acculturation modes and type 2 diabetes among native Hawaiians. Diabetes Care. 2008; 31(4):698-700. [PubMed: 18202248]

61. Jaber LA, Brown MB, Hammad A, Zhu Q, Herman WH. Lack of acculturation is a risk factor for diabetes in Arab immigrants in the US. Diabetes Care. 2003; 26(7):2010-2014. [PubMed: 12832304]

62. Afable-Munsuz A, Liang SY, Ponce NA, Walsh JME. Acculturation and colorectal cancer screening among older Latino adults: differential associations by national origin. J Gen Intern Med. 2009; 24(8):963-970. [PubMed: 19472016]

63. Afable-Munsuz A, Brindis CD. Acculturation and the sexual and reproductive health of Latino youth in the United States: a literature review. Perspect Sex Reprod Health. 2006; 38(4):208-219. [PubMed: 17162313]

64. Hunt LM, Schneider S, Comer B. Should "acculturation" be a variable in health research? A critical review of research on US Hispanics. Soc Sci Med. 2004; 59(5):973-986. [PubMed: 15186898]

65. Thomson MD, Hoffman-Goetz L. Defining and measuring acculturation: a systematic review of public health studies with Hispanic populations in the United States. Soc Sci Med. 2009; 69(7): 983-991. [PubMed: 19525050]

66. Kelly T, Yang W, Chen CS, Reynolds K, He J. Global burden of obesity in 2005 and projections to 2030. Int J Obes (Lond). 2008; 32(9):1431-1437. [PubMed: 18607383]

67. Shaw JE, Sicree RA, Zimmet PZ. Global estimates of the prevalence of diabetes for 2010 and 2030. Diabetes Res Clin Pract. 2010; 87(1):4-14. [PubMed: 19896746]

68. Kutty VR, Soman CR, Joseph A, Pisharody R, Vijayakumar K. Type 2 diabetes in southern Kerala: variation in prevalence among geographic divisions in a region. Natl Med J India. 2000; 13(6): 287-292. [PubMed: 11209482]

69. Misra A, Ganda OP. Migration and its impact on adiposity and type 2 diabetes. Nutrition. 2007; 23(9):696-708. [PubMed: 17679049]

70. Kaestner R, Pearson JA, Keene D, Geronimus AT. Stress, allostatic load, and health of Mexican immigrants. Soc Sci Q. 2009; 90(5):1089-1111. [PubMed: 21165158]

71. La Berge AF. How the ideology of low fat conquered America. J Hist Med Allied Sci. 2008; 63(2): 139-177. [PubMed: 18296750] 
72. Park Y, Quinn J, Florez K, Jacobson J, Neckerman K, Rundle A. Hispanic immigrant women's perspective on healthy foods and the New York City retail food environment: a mixed-method study. Soc Sci Med. 2011; 73(1):13-21. [PubMed: 21658831]

73. Akresh IR. Dietary assimilation and health among Hispanic immigrants to the United States. J Health Soc Behav. 2007; 48(4):404-417. [PubMed: 18198687]

74. Giskes K, van Lenthe F, Avendano-Pabon M, Brug J. A systematic review of environmental factors and obesogenic dietary intakes among adults: are we getting closer to understanding obesogenic environments? Obes Rev. 2011; 12(5):e95-e106. [PubMed: 20604870]

75. Sallis JF, Bowles HR, Bauman A, et al. Neighborhood environments and physical activity among adults in 11 countries. Am J Prev Med. 2009; 36(6):484-490. [PubMed: 19460656]

76. Auchincloss AH, Diez Roux AV, Mujahid MS, Shen M, Bertoni AG, Carnethon MR. Neighborhood resources for physical activity and healthy foods and incidence of type 2 diabetes mellitus: the Multi-Ethnic Study of Atherosclerosis. Arch Intern Med. 2009; 169(18):1698-1704. [PubMed: 19822827]

77. Chakraborty R, Ferrell RE, Stern MP, Haffner SM, Hazuda HP, Rosenthal M. Relationship of prevalence of non-insulin-dependent diabetes mellitus to Amerindian admixture in the Mexican Americans of San Antonio, Texas. Genet Epidemiol. 1986; 3(6):435-454. [PubMed: 3803913]

78. Schulz LO, Bennett PH, Ravussin E, et al. Effects of traditional and Western environments on prevalence of type 2 diabetes in Pima Indians in Mexico and the U.S. Diabetes Care. 2006; 29(8): 1866-1871. [PubMed: 16873794]

79. Jasso G, Massey DS, Rosenzweig MR, Smith JP. The New Immigrant Survey Pilot (NIS-P): overview and new findings about U.S. legal immigrants at admission. Demography. 2000; 37(1): 127-138. [PubMed: 10748994]

80. González Burchard E, Borrell LN, Choudhry S, et al. Latino populations: a unique opportunity for the study of race, genetics, and social environment in epidemiological research. Am J Public Health. 2005; 95(12):2161-2168. [PubMed: 16257940]

81. Martinez-Marignac VL, Valladares A, Cameron E, et al. Admixture in Mexico City: implications for admixture mapping of type 2 diabetes genetic risk factors. Hum Genet. 2007; 120(6):807-819. [PubMed: 17066296]

82. Barquera S, Tovar-Guzman V, Campos-Nonato I, Gonzalez-Villalpando C, Rivera-Dommarco J. Geography of diabetes mellitus mortality in Mexico: an epidemiologic transition analysis. Arch Med Res. 2003; 34(5):407-414. [PubMed: 14602508]

83. Lyngdoh T, Kinra S, Shlomo YB, et al. Sib-recruitment for studying migration and its impact on obesity and diabetes. Emerg Themes Epidemiol. 2006; 3:2. [PubMed: 16533387]

84. Alegria M. The challenge of acculturation measures: what are we missing? A commentary on Thomson \& Hoffman-Goetz. Soc Sci Med. 2009; 69(7):996-998. [PubMed: 19664868]

85. Markides, KS. Migration and health. In: Smelser, J, Baltes, PB, editorsInternational Encyclopedia of the Social and Behavioral Sciences. New York: Elsevier; 2001. 9799-9803.

86. Ayala GX, Baquero B, Klinger S. A systematic review of the relationship between acculturation and diet among Latinos in the United States: implications for future research. J Am Diet Assoc. 2008; 108(8):1330-1344. [PubMed: 18656573]

87. Lara M, Gamboa C, Kahramanian M, Morales L, Bautista D. Acculturation and Latino health in the United States: a review of the literature and its sociopolitical context. Annu Rev Public Health. 2005; 26:367-397. [PubMed: 15760294]

88. Portes A, Zhou M. The new second generation: segmented assimilation and its variants. Ann Am Acad. 1990; 1993:530. 


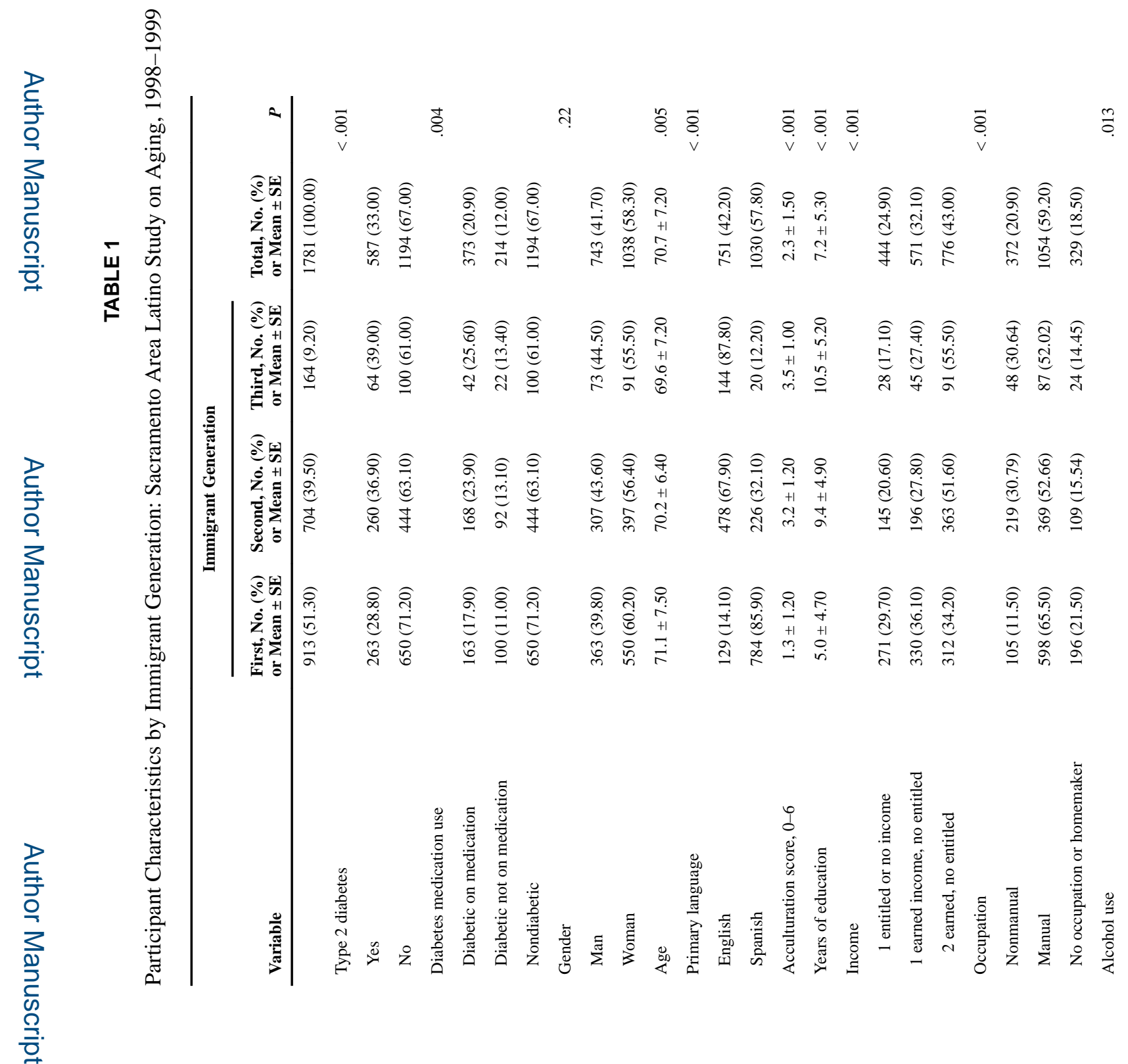

Am J Public Health. Author manuscript; available in PMC 2015 April 14. 


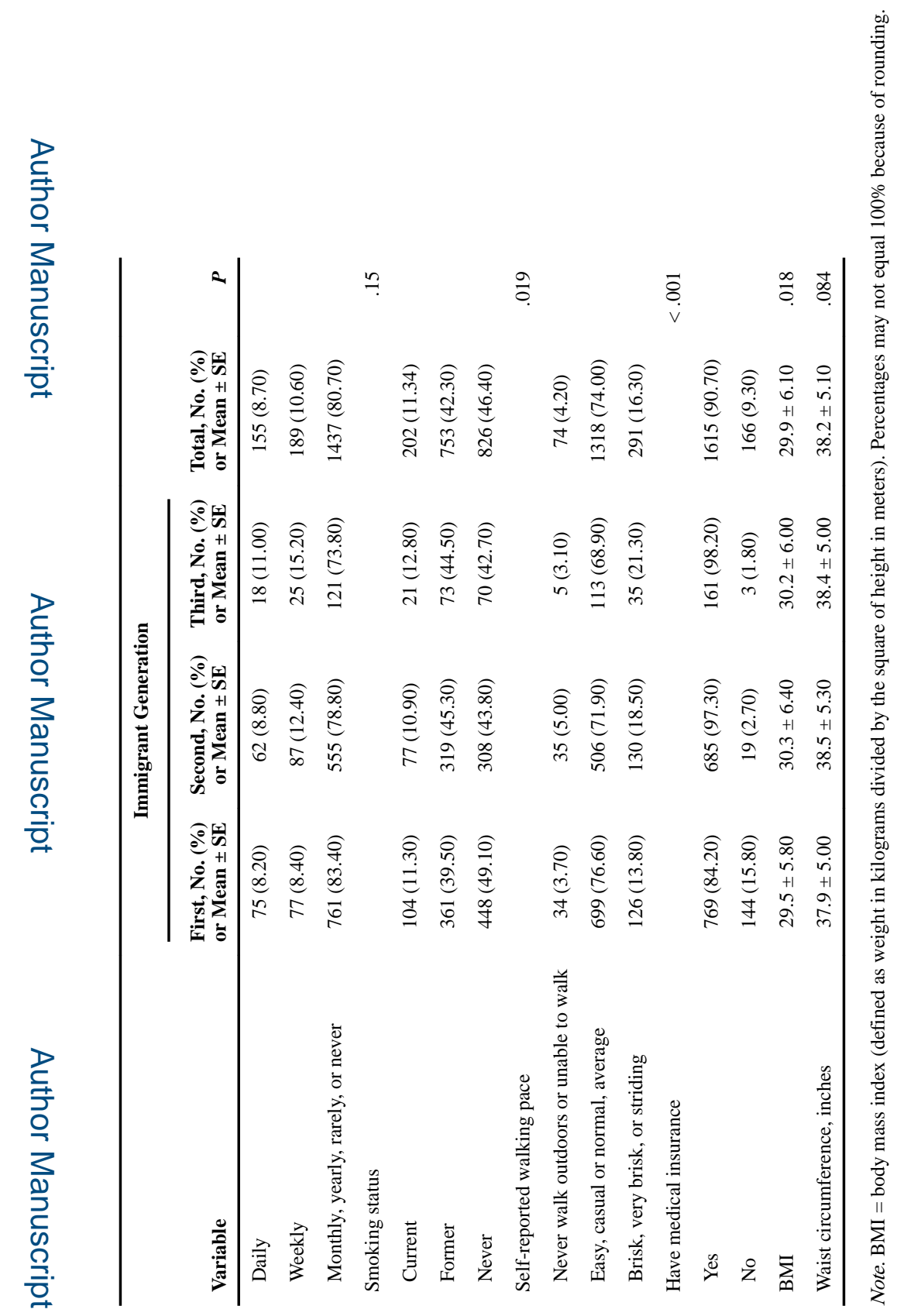

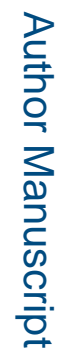

Am J Public Health. Author manuscript; available in PMC 2015 April 14. 
TABLE 2

Prevalent Diabetes: Sacramento Area Latino Study on Aging, 1998-1999

\begin{tabular}{|c|c|c|c|c|}
\hline Variable & $\begin{array}{l}\text { Base Model, } \\
\text { OR }(95 \% \text { CI })\end{array}$ & $\begin{array}{r}\text { Socioeconomic Status } \\
\text { Adjusted, OR (95\% CI) }\end{array}$ & $\begin{array}{r}\text { Lifestyle Adjusted, } \\
\text { OR (95\% CI) }\end{array}$ & $\begin{array}{l}\text { Full Model, } \\
\text { OR }(\mathbf{9 5 \%} \mathrm{CI})\end{array}$ \\
\hline \multicolumn{5}{|l|}{ Generation } \\
\hline Third & $2.09^{*}(1.423 .11)$ & $1.98^{*}(1.31,2.98)$ & $2.02 *(1.31,3.11)$ & $2.00^{*}(1.29,3.10)$ \\
\hline Second & $1.84^{*}(1.41,2.41)$ & $1.66^{*}(1.26,2.20)$ & $1.81^{*}(1.36,2.42)$ & $1.75^{*}(1.30,2.33)$ \\
\hline First (Ref) & 1.00 & 1.00 & 1.00 & 1.00 \\
\hline Acculturation & $0.88^{*}(0.80,0.95)$ & $0.93(0.83,1.03)$ & $0.92^{a}(0.84,1.01)$ & $0.95(0.85,1.06)$ \\
\hline Age & $1.00(0.98,1.01)$ & $1.00(0.98,1.01)$ & $0.99(0.97,1.01)$ & $0.99(0.97,1.01)$ \\
\hline \multicolumn{5}{|l|}{ Gender } \\
\hline Man & $1.19(0.97,1.45)$ & $1.11(0.88,1.39)$ & $1.36^{a}(1.07,1.73)$ & $1.44^{*}(1.11,1.86)$ \\
\hline Woman (Ref) & 1.00 & 1.00 & 1.00 & 1.00 \\
\hline Waist circumference, inches & & $1.07^{*}(1.05,1.10)$ & $1.08 *(1.05,1.11)$ & $1.08 *(1.05,1.10)$ \\
\hline Years of education & & $0.98(0.95,1.01)$ & & $0.98(0.95,1.01)$ \\
\hline \multicolumn{5}{|l|}{ No. of earned income sources } \\
\hline$\geq 2$ & & $0.74 *(0.57,0.98)$ & & $0.78^{a}(0.58,1.03)$ \\
\hline 1 & & $0.79(0.60,1.04)$ & & $0.76(0.57,1.01)$ \\
\hline 0 (Ref) & & 1.00 & & 1.00 \\
\hline \multicolumn{5}{|l|}{ Occupation } \\
\hline Manual & & $0.85(0.63,1.16)$ & & $0.83(0.60,1.14)$ \\
\hline No occupation or homemaker & & $1.04(0.72,1.51)$ & & $0.97(0.66,1.42)$ \\
\hline Nonmanual (Ref) & & 1.00 & & 1.00 \\
\hline \multicolumn{5}{|l|}{ Medical insurance } \\
\hline Yes & & $1.61^{a}(1.08,2.40)$ & & $1.49^{a}(0.99,2.24)$ \\
\hline No (Ref) & & 1.00 & & 1.00 \\
\hline \multicolumn{5}{|l|}{ Alcohol use } \\
\hline Frequent or moderate & & & $0.38^{*}(0.27,0.52)$ & $0.39^{*}(0.28,0.54)$ \\
\hline Occasional or never (Ref) & & & 1.00 & 1.00 \\
\hline \multicolumn{5}{|l|}{ Smoking } \\
\hline Current & & & $0.90(0.61,1.32)$ & $0.89(0.60,1.31)$ \\
\hline Former & & & $1.10(0.86,1.39)$ & $1.09(0.86,1.39)$ \\
\hline Never (Ref) & & & 1.00 & \\
\hline \multicolumn{5}{|l|}{ Walking activity } \\
\hline Brisk walker & & & $0.75^{a}(0.56,1.02)$ & $0.75^{a}(0.55,1.03)$ \\
\hline Casual, infrequent, or never (Ref) & & & 1.00 & 1.00 \\
\hline
\end{tabular}

Note. $\mathrm{CI}=$ confidence interval; $\mathrm{OR}=$ odds ratio.

${ }^{a}$ Variable approached statistical significance at $P<.1$.

$\stackrel{*}{*}<.01$. 